\title{
The Decomposed Border - the Integrated Application of Surrealism in Independent Animation
}

\author{
Kaili Xie ${ }^{1, *}$ Xiaoyu Huang ${ }^{1}$ \\ ${ }^{1}$ Xiamen Academy of Arts and Design, Fuzhou University, Xiamen, Fujian 361000, China \\ *Corresponding author. Email: 1016513721@qq.com
}

\begin{abstract}
Surrealism advocates the concept of breaking the restriction on the objective world and the normal logic, and it recommends the construction of the subconscious unlimited dreamy space with human's objective imagination, explores the inner world hidden at the deep layer, while the independent animation full of the creators' strong objective spirit serves the terrific carrier of this artistic genre. This paper attempts to start from such elements as the concepts and characteristics of surrealism, as well as the contents, forms and ideological connotation of the independent animation, and combine the surrealist artistic concept with the independent animation; moreover, it, on the basis of the fusion of both, discusses the decomposed border between the real world and the spiritual activities in the animation performance.
\end{abstract}

Keywords: Independent animation, Surrealism, Subconscious, Manifestations.

\section{INTRODUCTION}

At the beginning of the twentieth century, with the development of technology and the popularity of modern art, animation also came into being. Modern art advocates breaking the absolute representation of the real world in traditional painting, paying more attention to the expressive techniques of the spiritual world, and striving to criticize and subvert society metaphorically. Surrealism is an important genre of modern art, and its attention to the subconscious world has greatly affected the creation and development of independent animation, resulting in unlimited possibilities and innovation.

\section{OVERVIEW OF INDEPENDENT ANIMATION}

Independent animation is an art form relating to mainstream commercial animation, pursuing the expression of self-emotions and ideas. Independent animation advocates not sticking to conventions, but breaking the conventional fixed narrative mode and expression methods. Pi San, a leading Chinese independent animation character, said in the Interimage Space Studio in Beijing's 798 Art District: "Independence is not a gesture.
Independent animation is actually a hobby of animators. We use this to realize our dreams and express our feelings. It is the creator. Independent thinking and expression of interest in life and society are things that are alive. This is my criterion for judging independent animation." $\mathrm{Pi}$ San believes that independent animation may not even carry social value, and attached to any ideology, but mainly express the author's creativity, with an independent spirit and make unconventional creative attempts. It can be seen that, different from commercial animation, independent animation is the creative expression of creators in order to present personal observation and subjective feelings, focusing on the authorship of the artist.

At the same time, there are also many independent animation artists who seek the boundaries and ontological concepts of animation through the exploration of different visions and expressions. Thinking, concepts, and expression methods are its essential elements. Being experimental and pioneering are its unique labels. Therefore, independent animation is also called conceptual animation and pioneering animation.

The mainstream commercial animation has clear commercial goals and is based on the public's aesthetics and taste. Today's commercial animation 
has a mature production system and a standardized production process, but it will inevitably fall into the stereotype of modularity and single style. Independent animation is pursuing the exploration of new artistic fields and broad vision. The deadlock in animation plays an important role.

\section{THE CONCEPT AND CHARACTERISTICS OF SURREALISM}

French poet and critic André Breton defined surrealism as supernatural, unconscious, and irrational spiritual freedom. It is this kind of dream effect that surrealist artists strive for [1]. They use surreal thinking dreams as the source of pure aesthetic creation to express the human spiritual world. The dreams often show the mapping of the things that people desire most. Therefore, people's subconscious activities, accidental inspirations and dreams have become the objects of surreal artists deliberately [2].

Real life is full of many strict rules related to secular, moral, and legal constraints. People may have some guards that they don't notice. They often restrain and hide themselves with false words and pretentious behavior. It is disguised and not a real state. The famous psychologist Sigmund Freud believes that the state of complete relaxation in the surrealist dream reflects the most potential needs and considerations in the human heart. Surrealist artists also believe that in the subconscious state of dreams, the artistic creation performed is the complete expression of the real world and the true expression of the creator's heart. This kind of creative proposition is closer to people's subconscious thoughts and unconscious activities, and the atmosphere created is also true and illusion, making people feel that they are in reality and override reality.

The concept of surrealism has a profound impact on many art forms, especially in the field of visual art such as painting and animation, giving full play to its fantasy characteristics that are beyond reality and reason.

\section{THE DECOMPOSED BORDER}

Independent animation performs artistic on the basis of reality. It is not the pursuit of complete authenticity, but the pursuit of relative and biased aesthetics. Independent animation authors often add personal thoughts and experience of reality when creating an art space that is broader than reality.
Through subjective world imagination and combined processing, reality is mapped into the illusory world of animation works, allowing viewers Resonate [3]. This also requires creators to use more exaggerated deformation and unique creative methods, through fault-type processing, to exert their imagination and creativity, so that the audience can have a subconscious inner mapping of the real world. In order to express people's subconsciousness, surrealism casts aside the framework and constraints of the real world and breaks the shackles of rational thinking mode. Although in a rational and objective real world, surrealism integrates realistic concepts with people's subjective consciousness and dreams to discover the deep spiritual realm in the human heart, so as to explore the deep inner image of human beings.

It can be seen that the artistic concept of independent animation and the characteristics of surrealism to explore the subconscious world are similar. Because the two have similar properties and overlap in directions, independent animation and surrealism can be combined into one and penetrate each other, creating a boundary between the real world and spiritual activity, and this boundary can in turn give birth to There are many possibilities that are worth feeling and studying.

The fusion of surrealism in the creation of independent animation is a two-pronged approach, which is of great benefit to the artistic expression of independent animation concepts, narrative logic and expression forms.

\subsection{Broadening the Mind}

The concept of surrealism is dedicated to expressing the fusion of reality and subconsciousness. Therefore, the animated artwork created under the guidance of surrealism can allow audiences to better appreciate and understand the creator's inner world and enhance their own aesthetic ability [4]. Excellent independent animation, while having a unique form of external expression, also contains a deep spiritual ideological connotation, often condensing the creator's life experience and perception of subjects. Independent animation re-examined the boundary between real life and artistic expression, and conducted in-depth discussions on the expression of emotions, feelings and methods. In order to subvert traditional logic, creators established their own ways to reinterpret and interpret art. This is one of 
the characteristics of independent animation is also an in-depth extension of the concept of surrealism.

The integration of surrealism into independent animation emphasizes that illogical is also a kind of logic, but this illogical appearance is skillfully transformed into a logical form intended to break the traditional style. The combination of the two helps to get rid of the fixed thinking habits and limited concepts, and create new possibilities and innovations.

\subsection{Refactoring the Narrative Logic}

The application of surrealism to independent animation also brings new possibilities for the narrative style of animation. Different from the characteristics of commercial animation that output a large amount of information, independent animation has a variety of aesthetics, and often leaves a certain amount of white space for the audience to think and remember.

The absorption of surrealist artistic concepts in independent animation creation, and the integration of its strong characteristics of deconstruction and reorganization, collage exchange, time and space interlacing, etc., will help break the lens mode and routine that are obsessed with narration, and make the creation work from a single dimension Get out of the way, broaden the perspective of the creators to look at things, think about whether it can be expressed through some non-linear stream of consciousness emotions or atmospheres, and reconstruct innovative narrative logic.

\subsection{Rich Expression}

Independent animation is committed to exploring the nature of animation, the possibilities of animation performance, and different types of artistic expressions. In the context of surrealism, the free combination of various elements that exist in subconscious fantasy and dreams can also bring many new and unique ideas to independent animators and broaden the new perspective of independent animation performance. In this fusion creation, some animation expression methods with strong surrealist characteristics have also been produced, such as deconstruction and reorganization, absurd metaphors, interlaced time and space conversion, collage combination, etc., which greatly expands the expression boundary of independent animation.

\subsubsection{Deconstruction and Reorganization}

In the animated short film "Moznosti dialogu" by the Czech animation master Jan Svankmajer, a large number of bizarre and surreal elements and techniques are used ("Figure 1"). He is keen to give people the life of unexpected objects. The film has created three cross-character in multiple dimensions of time and space.

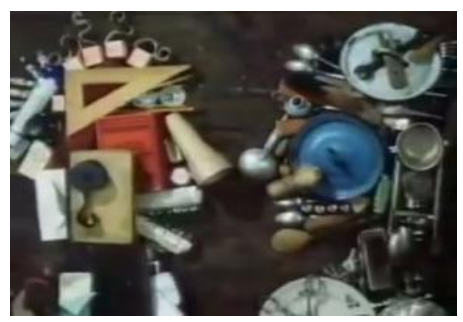

Figure 1 "Moznosti dialogu". Czekh. Jan Svankmajer. 1982.

In the first story, the "people" of various collages of fruits, vegetables, stationery, and tableware swallow each other and reorganize. This form with surreal elements that emphasizes decomposition, integration and reorganization breaks the rules in real life. To prompt the audience to produce a subconscious mapping experience what they really think.

The prize-winning work of the 2020 French Angci Animation Festival, "The Patron Saint of Place", uses a painting language full of decorativeness and cubism to deconstruct objects and plane shapes, and extract points, lines and surfaces to cleverly blend together ("Figure 2"). There is plenty of blank space for the scene to bring the audience Come with a sense of simplicity and long aftertaste.

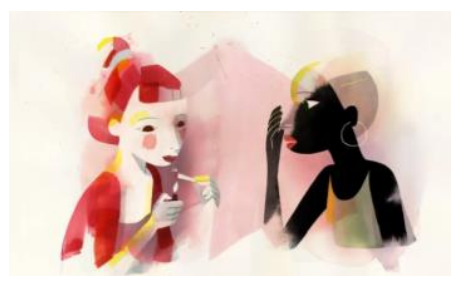

Figure 2 "The Patron Saint of Place". France. Adrian Merigeau. 2020.

\subsubsection{Absurd Metaphor}

In the stop-motion animation "Moznosti dialogu", Czech animation master Jan Svankmajer uses soil to shape the forms of men and women, and restores some of the relationship between men and women in reality through the entanglement of 
soil ("Figure 3"). The touch of soil appears to be real and dreamy. The illusion of the sence, the coexistence of the mud child and two adults after the joy reflects the characteristics of surrealistic time and space, which promotes the emotional externalization of the audience and is guided to plunge into the surrealistic space created by the author; the third paragraph In the story, Jan Svankmajer combined common objects into a combination, and used interesting animation language to express the conflict generated by the dialogue ("Figure 4"). The extremely bizarre combination of attributes and shapes brought strong visual impact and criticized human nature.

"Mountain Head" produced by Japanese animation master Mr. Koji Yamamura is a surreal independent animation with a fantasy nature ("Figure 5"). It freely incorporates personal style and subjective spirit in the animation creation, and usually keeps trial and error on different themes and exploration of different manifestations. So he adopted absurd metaphors and surreal elements as the tone of the film.

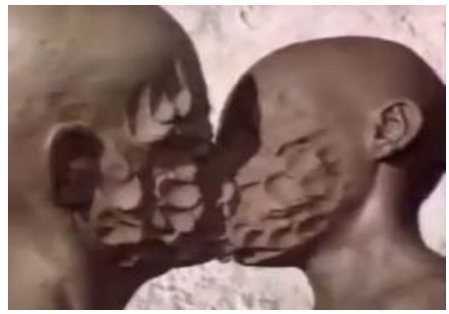

Figure 3 "Moznosti dialogu". Czekh. Jan Svankmajer. 1982.

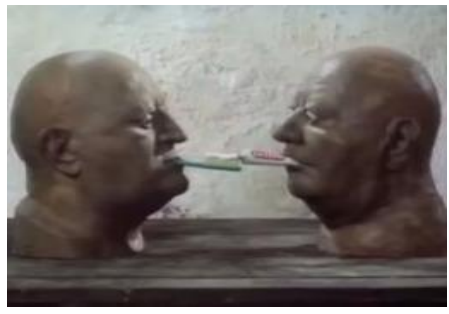

Figure 4 "Moznosti dialogu". Czekh. Jan Svankmajer. 1982.

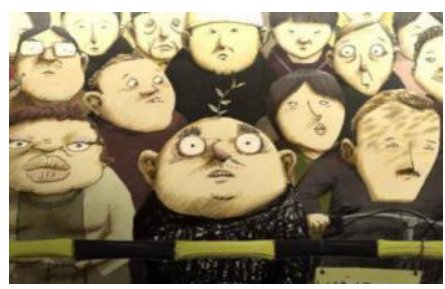

Figure 5 "Mountain Head". Japan. Koji Yamamura. 2002.
The author uses the cherry tree as a clue to place people's bad behavior on the head of the protagonist in a miraculous manner, and people flock to Mr. Head's head to play wildly. This artistic treatment that goes beyond objective reality seems unreasonable. It is not logical, but cleverly uses animation language to satirize the bad state of collective isolation and bullying that exists in the society, and the absurdity reveals the sorrow of human nature. The whole film is full of surrealist tonality, and many scenes that are contrary to the real life and seemingly illogical are put into the animation performance, which is reasonable. The plot of the animation is under the surrealism, so absurd and terribly real.

\subsubsection{Time-space Transition}

Surrealist animations are mostly based on the reality and dreams, and often use various expression methods such as push and pull lenses, light and shadow changes, tonal changes, and deformations to achieve the transition from reality to dreams and illusions [5].

The short animated film "Air! "Air!" applies the elements of dots, lines, planes and midlines in a variety of ways ("Figure 6"). There is only one line in the picture from the beginning to the end. According to the appearance of different objects such as plants, fish, birds and moles, the author makes the nature and function of space when the change occurs, the attributes of the line change to land, fish tank wall, antenna and so on.

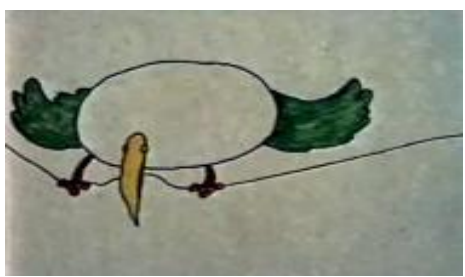

Figure 6 "Air! "Air!". Canada. Paul Driessen. 1972

Swiss animation master George Schweitzberg's animation "The Man without Shadow" is similar in terms of dimensionality and space expression ("Figure 7"). The opening uses the projection angle of light and shadow and the continuous rotation of the cube to establish the perspective of the whole film and the atmosphere of a visual labyrinth with a strong sense of lens. After that, the camera is continuously pushed and pulled from the cube, and it is naturally transformed into a building with column elements, leading to the protagonist. The movement of the lens, continuous transition 
deformation, and changes in spatial dimensions give the audience a flowing and comfortable visual experience. George Schweitzberg has brought into full play the artistic characteristics of Surrealism that transcend time and space. His other short film "Jeu" is also strongly experimental. The space in the room can be transformed into a hanging in the next second. The painting is lifted by the characters in the film, and the characters themselves can be directly deformed by matching actions in an instant, transforming clothing and even gender, with a strong irrational surrealistic color.

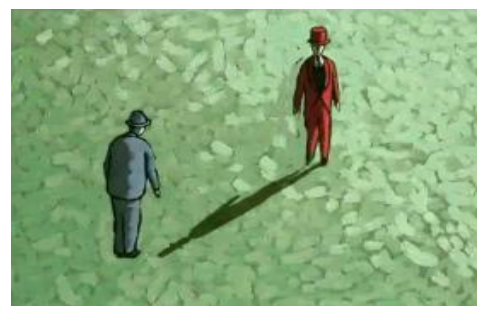

Figure 7 "The Man without Shadow".

Switzerland.Georges Schwizgebel. 2004.

The elements of surrealism are integrated into independent animation, and the flexible use of expression techniques creates a creative space for creators to give full play to free imagination, free from realistic experience and logical constraints, giving animation expression more possibilities and bringing audiences The in-depth visual and spiritual experience will make the audience re-examine and think.

\section{CONCLUSION}

Under the application of surrealist artistic concepts, whether it is the creative conception of animation or the specific form of expression, creators will be inspired to create more innovative ideas, so as to create more independent and profound animation works of art [6]. In the context of surrealism, it is easy to generate people's subconsciousness, which helps creators give full play to their imaginations, presenting them with interesting animation language and novel forms of pictures, expressing their inner world, dreams and reality freely. The gap between them has melted. Due to the parallel compatibility of the two themselves, the fusion and collision of surrealism and independent animation, this audio-visual feast will undoubtedly present an endless stream of shocking views.

\section{AUTHORS' CONTRIBUTIONS}

This paper is completed by Kaili Xie and Xiaoyu Huang. Kaili Xie wrote the manuscript, and Xiaoyu Huang contributed to revising and editing.

\section{REFERENCES}

[1] Li Sida. Introduction to Digital Media Art [M]. Tsinghua University Press, 2015.

[2] Li Sida. Introduction to Digital Media Art [M]. Tsinghua University Press, 2015.

[3] Zhang Yiqiong. A brief analysis of the characteristics and nature of animation art [J]. Popular Literature and Art (Theory), 2009(20): 108

[4] Tang Xiaoying. Analysis of the Surrealist Feelings of Animation[J]. Film Literature, 2011(22): 57-58.

[5] Li Nan, Peng Jie. Animated film-the natural carrier of surreal artistic conception[J]. Science and Technology Information, 2009(23): 160.

[6] You Yuanxue. Analysis of the Surrealistic Artistic Concept of Animated Films[J]. Western Radio and Television, 2019(23): 9596. 